\title{
EDITORIAL
}

\section{CARDIAC SURGERY AT A CROSS-POINT}

\section{Associate Professor Horațiu Moldovan, MD, PhD}

The cardiac surgery is the youngest surgical specialty that has emerged in the early period of the 20th century. Surprisingly, however, it is also the first surgical specialty that seems to be the first to disappear in a way or another in the second half of the 21 st century. Even if the optimists consider this will never happen, it is expected that cardiac surgery will suffer a radical metamorphosis, which makes the realists say that this field of surgery will actually disappear.

Before the beginning of the 20th century, the surgeons around the world have been convinced that human heart is untouchable. Remarkable surgeons of the 19th century like Theodor Billroth the founder of the Viennese school of surgery- said in 1863 that "Any surgeon that dares to perform surgery on the heart will fail and will lose the appreciation of his colleagues" [1]. This statement reveals the general opinion of that time, that the human heart is the center of the soul, of life itself and therefore it should never be touched. Considering this, Sharman stated in 1902 in „The American Journal of Medical Association" : "even though the heart lies at a few centimeters beneath the skin, it took 2400 years for surgery to reach this distance" [2].

Ironically, the same year that English surgeon Stephan Paget stated that "probably the human heart is boundary that nature set for any kind of surgery -1896- was also the year when Ludwig Rehn, a German surgeon from Frankfurt, managed to successfully repair a right ventricular wound, signing the birth certificate of the cardiac surgery [3]. Since then the myth that the human heart can't be touched by surgeons vanished and the sacred center of the heart has been opened...

Two distinct periods of cardiac surgery can be identified over the next 100 years. The first period is the so called "surgery on a closed heart", before the invention of extracorporeal circulation. In this heroic period, the first interventions that involved the pericardium were performed.

In the first years of the 20th century, Alexis Carell imagined the experimental basis of cardiovascular surgery. He invented the vascular sutures, demonstrated the possibility of organ transplantation and imagined coronary surgery. As recognition of his fundamental work he received the Nobel prize for medicine and physiology in 1912. Although he never performed surgery on humans, Alexis Carell remains to this day the first surgeon in history that was awarded with this prestigious prize [4].

Surgery of the pericardium started in 1920 with Ludwig Rehn and Ferdinand Sauerbruch [5]. The first surgical approach of the aortic valve was realized by Theodor Tyffier in Paris in 1912 [6]. He succeeded to enlarge an aortic stenosis through a purse on the anterior wall of the aorta. In 1923, in Boston, USA, Elliot Cuttler realized the first instrumental mitral valve valvulotomy on a 12 year old girl [7]. Using a specially modified forceps, and the apex of the left ventricle as the initial approach, he managed to successfully open the mitral valve commissures and then to close the incision on the left ventricle. The first digital mitral valve commissurotomy through the left appendage was performed in 1925 by Sir Henry Soutar[8]. Catastrophic results ( $90 \%$ mortality) lead surgeons to abandon this procedure for the next 25 years. In 1948, Charles P. Bailey (Philadelphia), Dwight E. Harken (Boston) and Russell Brock (London) realized the first successful mitral valve commissurotomy $[9,10]$.

The first ligature of patent arterial duct was performed by Robert Edward Gross. This procedure took place at Harvard Medical School and Children's Hospital from Boston, Massachusetts, in 1938 [11]. 
Palliative treatment of the Fallot tetralogy started with the first systemic-pulmonary shunt, realized by Alfred Blalock in 1944 at John Hopkins Hospital [12]. The idea of subclavio-pulmonary anastomosis was born with the contribution of Hellen Taussig, founder of pediatric cardiology.

Treatment of aortic coarctation was independently realized by Edward Gross and Clarance Crafoord in 1945. Both surgeons managed to excised the diseased segment of the aorta and then performed an end to end anastomosis of the aorta [13].

Sir Thomas Holmes-Sellors in 1947 and Russel Brock in 1948 realized the first pulmonary valve valvulotomy [10].

In our country, professor Nicolae Hortolomei was the first to perform surgery on the heart at Coltea Hospital. He legated a patent arterial duct, excised an aortic coarctation and successfully realized in 1953 a digitally mitral valve commissurotomy [14].

The second period of cardiac surgery began with the developing of the extracorporeal circulation. This technology allowed stopping the heart and keeping the patient alive, using a device that manage to circulate and oxygenate the blood. This ensemble composed of a pomp and an oxygenator was called "the extracorporeal circulation machine" and made possible the future development of "open cardiac surgery".

In 1946 Wilfred G. Bigelow (Toronto, Canada ), demonstrated the role of hypothermia in increasing the tissue resistance to hypoxemia. This concept is fundamental in the development of extracorporeal circulation [15]. The first procedure on an open heart was realized by John Lewis from University of Minnesota, Mineapolis USA, on 2 september 1952. He used profund hypotermia and occlusion of the caval veins, without using extracorporeal circulation. Using this technique he closed an interatrial septal defect in a 6 year old boy. Time was his biggest limitation, because the heart could not be stoped for more than 8-10 minutes.

On 6 may 1953, John H. Gibbon realised the first open heart surgery using an extracorporeal circulation machine [16]. He succesfully closed and interatrial septal deffect on an 18 years old girl. Unfortunatly he lost the following 4 patients, and he decided to abandon this king of surgery after 20 years of research.

A year later, on the 26th of March 1954 at „University of Minesotta” from Mineapolis USA, C. Walton Lillehei closed an inteventricluar septal defect on a child using the so called "crossed circulation technique". In this procedure, he connected the patient's circulaton to his father circulation, trying to repoduce the fetal circulation [17]. Using this technique he operated 45 patients, being the first surgeon that closed ventricular septal defects, corrected the common atrioventricular canal and treated the Fallot tetralogy. Finding a compatible match for the "cross circulation" was the biggest limit of this technique. This method was untill the developement of liver and renal transplant, the only kind of surgery that could reach $200 \%$ mortality rate and was abandoned later due to ethical considerations.

Starting from 1955, John Kirkling (Mayo Clinic), used the extracorporeal circulation machine (pomp - oxigenator) [18]. He used the Mayo-Gibbon-IBM type, and this technology began to be used all over the world.

In Romania, the first surgical procedure on the heart using an extracorporeal circulation machine was realized in 1961 at Fundeni Hospital (Bucharest). A remarkable team composed of professor Voinea Marinescu and professor Dan Setlacec, closed an atrial septal defect on an 18 years old boy. The extracorporeal machine was handled by Marian Ionescu, and the anesthesia was managed by professor George Litarczek. The patient is still living.

Surgery of the cardiac valves started in 1960 when Albert Starr realized the first mitral valve replacement [19].

Without a doubt coronary artery bypass grafting is the most widly spread type of cardiac surgery. Initially introduced by Michael DeBakey and later perfected by Renee Favaloro in 1960, this procedure remains one of the most frequent and best studied type of surgery in medicine [20].

A crucial moment in the history of cardiac surgery is represented by the first cardiac transplant on human performed by Christian Barnard in 1967[21]. This achievement consecrate cardiac surgery as a high performace field and made the cardiac surgen a public figure. In this moment, the 
love story between cardiac surgery and media started. Most probably the majority of active cardiac surgeons of this generation owe Christiaan Barnard their option for choosing this field and this medical specialty her huge succes.

It is considered that the maximum moment of cardiac surgery is the year 1986 when worldwide over 2000 procedures on the open heart were performed daily.

But new discoveries started to appear in the cardiovascular field. In the 70 s percutaneous procedures were invented. Andreas Gruntzig realized in 1977 the first coronary angioplasty and coronary stents were implanted in 1986 by Puel and Sigwart. Development on interventional cardiology was exponential and nowadays at the European Association of Cardiothoracic Surgery simposium about the future of cardiac surgery, $90 \%$ of the cardiac surgeons stated that they would prefer the coronary stent over coronar artery bypass grafting surgery if they would have to choose as patients.

Starting with 2003 when was realised the first transcatheter aortic valve implantation (TAVI), the exclusive field of cardiac valve surgery is partialy claimed by interventional cardiology [23].

The field of aortic anevrisms and acute dissections falls from cardiac surgery also to interventional cardiology after the developement of endoaortic stent grafts [24,25].

As a consequence the number of coronary artery bypass grating procedures falls $28 \%$ between 1997 and 2004 in the USA. Meanwhile coronary percutaneos procedures rises with $121 \%$ [24,28]. Also it is possible that for the first time in history, the number of cardiac surgeons will decrease untill 2020 [24.28].

But cardiac surgery extends in to new fields in order to survive. For exemple, one of the future aspect is the treatment of cardiac insuffiency. It is estimated that over 5 milion americans have cardiac insuffiency [26] and cardiac transplantation is the solution for these patients. Unfortunately, the number of donors falls, and this is no longer an effective solution. Multiple devices are designed in order to help the heart, ranging from univentricular asist devices to artificial hearts. This devices can act as a bridge to cardiac transplantation or they can be the solution for patients that are not eligible for cardiac transplantation.

Surgical treatment of atrial fibrilation remains a solid options for patients with this disease which have a high risk of emboly or progression to cardiac insufficiency [27].

The field of corection of congenital cardiac malformations lessens because of early diagnostic and possibility to end the pregnancy. But there are surgical treatments for children that are born with complex congenital heart malformations with optimal results.

The development of minimally invasive techniques, robotics and hybrid ones represents the response of cardiac surgery to interventional cardiology.

Apparently, cardiac surgery and interventional cardiology are merging. More and more patients are heald in hybrind operating rooms, using hybrid techniques. The concept of "heart teams" emerges- a team made of cardiologists, cardiac surgeons and cardiac anesthesiologists. Probably, in the future will exist only a cardiologist-cardiac surgeon or a cardiac surgeon-cardiologist, either way a specialist in cardiovascular medicine.

The conclusion isn't pessimistic. As long as there will be patients, doctors will be needed. It remains to be seen if they will be surgeons, interventional cardiologists or just cardiologists.

Certainly, general anesthesia, opeaning the mediastinum through median sternotomy using an electic saw and circulating the patients blood through the extracorporeal circulation machine, not to mention stopping the heart, isn't the future.

But introducing needls in arteries, wires in the aorta and pen sprins into the coronary isn't also the future.

Without a doubt, the future belongs to physicians that will cure cardiovascular disease with pills or even better just with advices... 


\section{References}

[1]M K Davies and A HollmanHistory of cardiac surgery, Heart. 2002 Jun; 87(6): 509.

[2]End A, Wagner E. The Heart: location of the human soul - site of surgical intervention. J Card Surg. 1993;8(3):398-403.

[3]Stephenson Larry W. History of Cardiac Surgery . vol. 7. New York: Springer; 2008:1471 1479

[4]Nobel Lectures, Physiology or Medicine 1901-1921, Elsevier Publishing Company, Amsterdam, 196

[5]Shumacker HB Jr When did cardiac surgery begin?, J Cardiovasc Surg (Torino). 1989 MarApr;30(2):246-9.

[6]Chas. L. Gibson, THEODORE TUFFIER 1857-1929, Ann Surg. 1930 Apr; 91(4): 636-637.

[7]Frederick P. Ross, "Master Surgeon, Teacher, Soldier and Friend: Elliott Carr Cutler, MD (1888-1947)," AMERICAN JOURNAL OF SURGERY 137 (1979): 428-32. C

[8]Comas GM1, Widmann WD, Hardy MA. Curr Surg. 2006 Nov-Dec;63(6):476-81. The legacy of Sir Henry Souttar: pioneer of the first mitral valvulotomy.

[9]Denton A. Cooley, MD; O. H. Frazier, MD The Past 50 Years of Cardiovascular Surgery, Circulation. 2000; 102: Iv-87-Iv-93

[10]Brock RC. The surgery and pathological anatomy of the mitral valve. Br Heart J . 1952;14:489 -513

[11]Gross RE, Watkins E. Surgical closure of atrial septal defects. Arch Surg 1953;67:676 - 685

[12]Blalock A, Taussig HB. The surgical treatment of malformations of the heart in which there is pulmonary stenosis or pulmonary atresia. JAMA .1945;128:189-202

[13]Kvitting JP1, Olin CL. Ann Thorac Surg. Clarence Crafoord: a giant in cardiothoracic surgery, the first to repair aortic coarctation. $2009 \mathrm{Jan} ; 87(1): 342-6$.

[14]NICOLAE HORTOLOMEI (1885-1961) 125 DE ANI DE LA NASTERE Jurnalul de Chirurgie, Iaşi, 2010, Vol. 6, Nr. 4 [ISSN 1584 - 9341]567 [15] Barbara Kermode-Scott, Wilfred G Bigelow BMJ. 2005 Apr 23; 330(7497): 967.

[16]Gibbon JH. Application of a mechanical heart and lung apparatus to cardiac surgery. Minn Med. 1954;37:171-180.

[17]Lillehei CW. Controlled cross circulation for direct-vision intracardiac

surgery: correction of ventricular septal defects, atrioventricularis communis, and tetralogy of Fallot. Postgrad Med J. 1955;1:388 -396.

[18]Kirklin JW, DuShane JW, Patrick RT. Intracardiac surgery with the aid of a mechanical pumpoxygenator system (Gibbon type): report of eight cases.Mayo Clin Proc. 1955;30:201-206

[19]Starr A. Total mitral replacement: fixation and thrombosis. Surg Forum.1960;11:258 -260.

[20]Favaloro RG, Effler DB, Groves LK, et al. Severe segmental obstruction of theleft main coronary artery and its divisions: surgical treatment by the saphenous vein graft technique.J Thorac Cardiovasc Surg. 1970;60:469- 482

[21]Barnard CN. The operation: a human cardiac transplant: an interim reportof a successful operation performed at Groote Schuur Hospital, CapeTown.S Afr Med J. 1967;41:1271-1274

[22]Monagan D, Williams DO. Journey into the Heart: A Tale of Pioneering Doctors and Their Race to Transform Cardiovascular Medicine.,New York, NY: Gotham Books; 2007.2. King SB. Angioplasty from bench to bedside to bench. Circulation1996;93:1621-1629

[23]Leacche M, Umakanthan R, Zhao DX et al.: Hybrid Procedures, Do They Have a Role ? Circ Cardiovasc Inter 2010; 3:511- 18

[24]England A, McWilliams: Endovascular Aortic Aneurysm Repair (EVAR). Ulster Med J 2013;82(1):3 10

[25]Hughes GC: Endovascular Repair Will Be the Best Option for Thoracoabdominal Aortic Aneurysm in 2020. Texas Heart Institute Journal 201239 (6): 834 - 35

[26]Weisse AB: Cardiac Surgery: A Century of Progress. Texas Heart Institute Journal 201138 (5): 486 - 90

[27]Robertson JO, Lawrance CP, Maniar HS et al.: Surgical Techniques Used for the Treatment of Atrial Fibrillation. Circulation Journal 2013 77: 1941 - 51

[28]Grover A, Gorman K, Dall TM et al.: Shortage of Cardiothoracic Surgeons is likely by 2020. Circulation 2009 120:488-494 